Impact of agricultural input subsidies on food and nutrition security

This is the version of the article accepted for publication in Food Security published by Springer:

https://doi.org/10.1007/s12571-018-0857-5

Accepted version downloaded from SOAS Research Online: http://eprints.soas.ac.uk/30106

\title{
The impact of agricultural input subsidies on food and nutrition security: A systematic review
}

Running page title: Impact of agricultural input subsidies on food and nutrition security

\section{Helen L Walls ${ }^{12}$ - Deborah Johnston ${ }^{23} \cdot$ Mehroosh Tak $^{23}$ • Jane Dixon ${ }^{4} \cdot$ Johanna Hanefeld $^{1}$ - Elizabeth Hull ${ }^{23}$ - Richard D Smith ${ }^{12}$}

\author{
${ }^{1}$ London School of Hygiene \& Tropical Medicine, 15-17 Tavistock Place, London WC1H 9SH, United \\ Kingdom \\ ${ }^{2}$ Leverhulme Centre for Integrative Research on Agriculture \& Health, 36 Gordon Square, London \\ WC1H OPD, United Kingdom \\ ${ }^{3}$ School of Oriental \& African Studies, University of London, 10 Thornhaugh Street, Russell Square, \\ London WC1H OXG, United Kingdom
}

${ }^{4}$ Australian National University, Acton, ACT 2601, Australia

\section{Corresponding author}

Helen Walls, helen.walls@lshtm.ac.uk, 07404420189

\begin{abstract}
Agricultural input subsidies, a form of social protection, are often considered an important means of improving agricultural productivity in low- and middle-income countries. However, their effectiveness and efficiency remains contentious with respect to productivity, economic and consumer welfare measures, as well as food and nutrition security. This is exacerbated by a weak evidence base, including no review focused on the impact of agricultural input subsidies on food security and nutrition. Further, where studies have considered nutritional outcomes of agricultural input subsidies interventions, this has often been in regard to changes in consumption of the targeted staple food, measured in terms of calorie consumption or a similar measure of changes in energy availability, ignoring other aspects of malnutrition, including impacts on dietary diversity. This wider consideration of impacts on dietary diversity is important, given the increasing recognition in nutrition policy of the importance of dietary diversity. We address this gap in the literature with a review of the evidence on the impact of agricultural input subsidies programmes on food and nutrition security in low- and middle-income countries, mapping this evidence against a conceptual framework of the mediating pathways.
\end{abstract}

Keywords Agricultural input subsidy · Social protection - Nutrition · Health 



\section{Background}

Agricultural input subsidies (AISs), a form of social protection, are often considered an important means of improving agricultural productivity in low- and middle-income countries (LMICs) (Gordon 2000). In recent years, there has been a resurgence of interest and investment in AISs, mainly in Africa (Morris et al. 2007; Jayne and Rashid 2013), resulting from the need to boost agricultural productivity and food security. However, there is considerable debate regarding their impact on nutrition and health outcomes.

In many LMICs, poor farmers are unable to afford the inputs and technologies needed to increase productivity; an important means of improving food security (Wiggins and Brooks 2010). Thus, AISs - which we define here as a grant (or loan, if repaid below market prices) given to reduce the cost of acquiring a specific input used in agricultural production, for example, inorganic fertiliser or hybrid seeds (Ecker and Qaim 2011) - are a way of incentivising farmers to purchase inputs they are unable or unwilling to obtain at market rates. Thus, AISs are considered a means for achieving higher agricultural productivity, improved food security and, through lower food prices, pro-poor economic growth. However, such results are not guaranteed nor so clear-cut. There is considerable contention among policy-makers and analysts regarding the effectiveness and efficiency of AIS investments and the conditions under which they work (Dorward et al. 2015). This contention is especially focused upon productivity, economic and consumer welfare measures, catalysing a review of this impact that was conducted by Dorward et al. (2015).

Previous reviews of agricultural interventions (not just input subsidies) on child nutritional status have found mixed results or no impact (Ruel 2001; Berti et al. 2003; Leroy and Frongillo 2007; World Bank 2007; Kawarazuka 2010; Masset et al. 2011). The most recent of these reviews, by Masset at al. (2011) attributed this lack of positive impact to methodological weaknesses in the studies rather than characteristics of the interventions (Masset et al. 2011). Thus, whilst some studies have reviewed aspects of the impact of agricultural interventions on nutrition and health, there has not been a review focused on the impact of AISs on food security and nutrition. Given the financial resources devoted to AISs, often with intended consequences for food security and nutrition in many countries, this is thus an important area to be addressed.

Further, there is increasing recognition in agricultural policy that the focus on staple crops can be to the detriment of wider nutrition, because of the lack of micronutrients in many staples. This wider consideration of impacts on dietary diversity rather than on a single crop staple is important, given the increasing recognition in nutrition policy of the importance of dietary diversity (Burchi et al. 2011; Thompson and Meerman 2013; Koppmair et al. 2017). As well as different nutritional impacts, the various pathways of impact have not been consistently explored. For example, through direct impacts on food consumption patterns, or those that may come about through improved household incomes allowing for the purchase of a more diverse diet (Turner et al. 2013; Kanter et al. 2015).

This paper addresses this clear knowledge gap by reviewing the evidence on the impact of AIS schemes on food and nutrition security in people of all ages in LMICs. This evidence was mapped against a conceptual framework of the pathways, to examine the pathways addressed and not addressed by this evidence, and key characteristics of these studies. 


\section{Methods}

This project involved the following steps:

\subsection{Development of a conceptual framework}

We adapted the conceptual framework of Dorward et al. (2015), taking into account other relevant frameworks in this area (UNICEF 2010; Kanter et al. 2015), to include key pathways from AISs to nutrition and nutrition-related health.

\subsection{Systematic review}

The systematic review was based on the following inclusion criteria:

"All full-text publications, published or grey literature, with English abstracts are included in the study that describe, correlate, quantify or model the impact of agricultural input subsidies on nutrition and/or nutrition-related health in low- and middle-income countries."

Given that a systematic search protocol identifying articles related to the impact of specific AISs on a range of outcomes in LMICs had already been undertaken by Dorward et al. (2015), we decided that it would be relevant to our purposes of our review, with the addition of extra search criteria. Thus, we adapted the Dorward et al. (2015) review by restricting the results of their review to publications addressing nutrition and nutrition-related health outcomes.

The Dorward team identified relevant studies among both published and unpublished literature, by searching scientific databases (3ie Systematic Review Database; Ageconsearch (http://ageconsearch.umn.edu/); Agricola; AGRIS; British Library for Development Studies; CAB Direct; Dissertations Express (http://disexpress.umi.com/dxweb); Ebsco: Econlit and Africa Wide; ELDIS; IDEAS (Economic and Finance Research), including the RePec database http://ideas.repec.org/; IFPRI library; JOLIS; Networked Digital Library of Theses and Dissertations (NDLTD) (www.theses.org); Social Sciences Citation Index (ISI Web of Knowledge); USAID library; USDA's Economic Research Service site), other information sources including grey literature (Google Advanced Search); Google Scholar; OECD/DAC Evaluation database; Open-Grey) and hand-searching various journals (Agricultural Economics; American Economic Review; American Economic Journal Applied Economics; American Journal of Agricultural Economics; Economic Development and Cultural Change; European Review of Agricultural Economics; Journal of Agricultural Economics; Journal of Development Economics; World Development). The search terms used in the Dorward search are described in Table 1.

Table 1 Search terms applied in the Dorward review

\begin{tabular}{|l|l|}
\hline Geography & (LDC* OR LIC OR LICs OR LMIC* OR "developing countr*" OR "low income countr*" \\
& OR "third world countr*" OR "Latin America" OR Afghanistan OR Bangladesh OR \\
& Benin OR "Burkina Faso" OR "Burkina-Faso" OR Burundi OR Cambodia OR "Central \\
& African Republic" OR Chad OR Comoros OR Congo OR Eritrea OR Ethiopia OR \\
& Gambia OR Guinea OR "Guinea-Bissau" OR "Guinea Bissau" OR Haiti OR Kenya OR \\
& "North Korea" OR "Democratic Republic Korea" OR "Democratic People's Republic \\
& Korea" OR Kyrgyzstan OR "Kyrgyz Republic" OR Liberia OR Madagascar OR Malawi \\
& OR Mali OR Mozambique OR Myanmar OR Nepal OR Niger OR Rwanda OR "Sierra \\
& Leone" OR Somalia OR "South Sudan" OR Tajikistan OR Tanzania OR Togo OR \\
& Uganda OR Zimbabwe OR Rhodesia OR Armenia OR Bhutan OR Bolivia OR \\
& Cameroon OR "Cape Verde" OR Congo OR "Ivory Coast" OR "Cote d'Ivoire" OR \\
& Djibouti OR Egypt OR "El Salvador" OR Georgia OR Ghana OR Guatemala OR Guyana \\
\hline
\end{tabular}




\begin{tabular}{|l|l|}
\hline & OR Mauritania OR Honduras OR Indonesia OR India OR Kiribati OR Kosovo OR Lao \\
OR Laos OR Lesotho OR Micronesia OR Moldova OR Mongolia OR Morocco OR \\
Nicaragua OR Nigeria OR Pakistan OR "Papua New Guinea" OR Paraguay OR \\
Philippines OR Samoa OR "Sao Tome" OR Senegal OR "Solomon Islands" OR "Sri \\
Lanka" OR Sudan OR Swaziland OR Syria OR "Syrian Arab Republic" OR "East Timor" \\
OR "Timor Leste" OR "Timor-Leste" OR Ukraine OR Uzbekistan OR Vanuatu OR \\
Vietnam OR Gaza OR "West Bank" OR Yemen OR Zambia) AND ("agricultur*" OR \\
"farm*") \\
AND
\end{tabular}

This search was conducted in April 2015. Further details on the Dorward search strategy are available in their study protocol (Dorward et al. 2015). We then adapted the Dorward et al. (2015) search strategy, developing definitions relevant to the purposes of our search and adding additional search criteria, as described below.

We describe AIS programmes and policies as those policies/programmes designed explicitly to reduce the input cost of agricultural activities. Specifically, 'agricultural input subsidies' were defined as grants (or loans, if repaid at below the market price) given to a farmer as a means of reducing the market price of a specific input used in agricultural production. Credit and loans for unspecified purposes were not included as they have distinct economic effects, as covered in a much broader literature. We also excluded early-stage agricultural research station field trials and humanitarian relief programmes, as the adoption of these trial inputs and such emergency interventions are unrepresentative of normal agricultural practice. Interventions studied were limited to direct agricultural producer subsidies for inputs. We also excluded studies of large agricultural changes that may have included an AIS component, for example studies of the 'green revolution', because they contained multiple components that would make it difficult to isolate the impact of the AIS programme.

The primary outcomes of interests in our review were human nutritional and health outcomes. We defined nutrition outcomes as macro- or micronutrient dietary components (for example, protein, carbohydrate, fibre, vitamins) or related descriptions of nutritional intake (for example diet, nutrition, nutrient or micronutrient intake). We defined health outcomes as anthropometric indicators related to nutrition (e.g. height, weight, body mass index, stunting) or health outcomes (for example, heart disease, stroke, hypertension, blood glucose, disabilityadjusted life years). To avoid overlap with the Dorward et al. systematic review we restricted our outcome variables to nutrition and health outcomes only and excluded outcome variables related to the wider food environment (and potentially, relating to consumer welfare and economic outcomes), such as food availability, access, utilisation and price. However, whilst studies were only included if they addressed these outcomes of interest, in those studies that we did include we also considered secondary outcomes related to food environments, to help us understand the pathways 
of impact proposed in the study. Secondary outcomes were only collected from papers that report primary outcomes of interest.

All references were added to an EndNote database and duplicates removed. Searches and the screening process were duplicated by two researchers (MT and either HLW or DJ) in order to reduce researcher bias, however where we reached agreement on over $90 \%$ of articles sampled $(10 \%)$ in a step of the screening process, single-screening was conducted (MT). Discrepancies were resolved through discussion between the three reviewers.

\subsection{Data extraction and analysis}

We compiled a database of the studies identified for inclusion in our review containing details on study author, year and format of publication, country or region, data type, year(s) for data collection, broad statistical modelling methods, types of AIS, description of outcome measures, effect size estimated and study conclusion. Three researchers (HW, DJ, MT) extracted and crosschecked the data for all included studies and discrepancies were resolved through discussion.

For the analysis, the included studies were differentiated by AIS type, country or region, methods applied, outcome measures used, result of the analysis and pathway addressed. There is substantial variability in all these aspects between studies, and traditional statistical analyses of the reported numerical findings in the included studies, such as meta-analysis, would not provide meaningful results. Thus, we provide a narrative synthesis of these studies and discuss the main emergent patterns, based on these key categories of interest. 'Narrative synthesis' techniques are often considered more effective than meta-analysis and standard systematic review methods for understanding pathways to impact (Thomas and Harden 2008; Snilstveit et al. 2012). These techniques involve organising the study findings around key themes and exploring patterns in both quantitative and qualitative data. Rather than undertaking a quantitative assessment of the quality of evidence in terms of a quality 'score', we have commented on the quality of the evidence in our narrative analysis.

\subsection{Mapping of studies and study analysis}

We described the studies identified in terms of the pathways of the conceptual framework developed in A) (see Fig. 2). For the included studies, we then examined the pathways of the conceptual framework addressed by the studies, and the gaps, including by key themes and methods and metrics applied. Metrics analysis was used to look at the various input and outcome measures used.

\section{Results}

\subsection{Conceptual framework}

Figure 1 presents the conceptual framework we developed for assessing the relationships between AISs and nutrition and related health. Its development was based on a synthesis of key pathways from the Dorward et al. (2015) framework for assessing the economic and consumer welfare impacts of AISs (Dorward et al. 2015), the UNICEF framework for assessing the determinants of 
malnutrition (UNICEF 2010), and the Kanter framework (Kanter et al. 2013) for conceptualising the links between agriculture and food system policies, and nutrition and health. The resulting framework depicts the various pathways, including those more indirect, from AIS programmes to nutrition and health.

Specifically, the framework describes key pathways from AISs to nutrition and related health through changes in: agricultural production, and related impacts on household cash income (for example if a household raises its agricultural productivity it may then be able to sell produce in the market, or sell more produce in the market), household behaviour (any impact of an AIS programme on nutrition and health will affect household behaviour, including for example women's time to spend on childcare or other activities (Johnston et al. 2017)); government revenue and spending (if agricultural production increases of a cash crop with an export tax applied, this will influence government revenue and likely, spending on public services, including the provision of social support, and school food programmes), and public service provision and hygiene and sanitation standards make up what can be termed the 'health environment', which encapsulates wider environmental influences on health, and thus has flow-on affects for nutrition and related health. The direct link between AISs and changes in the 'health environment' could be brought about by a subsidy on water on pesticide, which could increase malaria risk through supporting the growth of malarial mosquito populations, or health risks from environmental pollution, respectively. Many of these domains such as 'impacts on household income', 'impacts on household behaviour' and 'impacts on government revenue (spending) affect nutrition and related health via changes in food and non-food consumption.

Fig. 1 Conceptual framework of key pathways from agricultural input subsidies to nutrition and related health

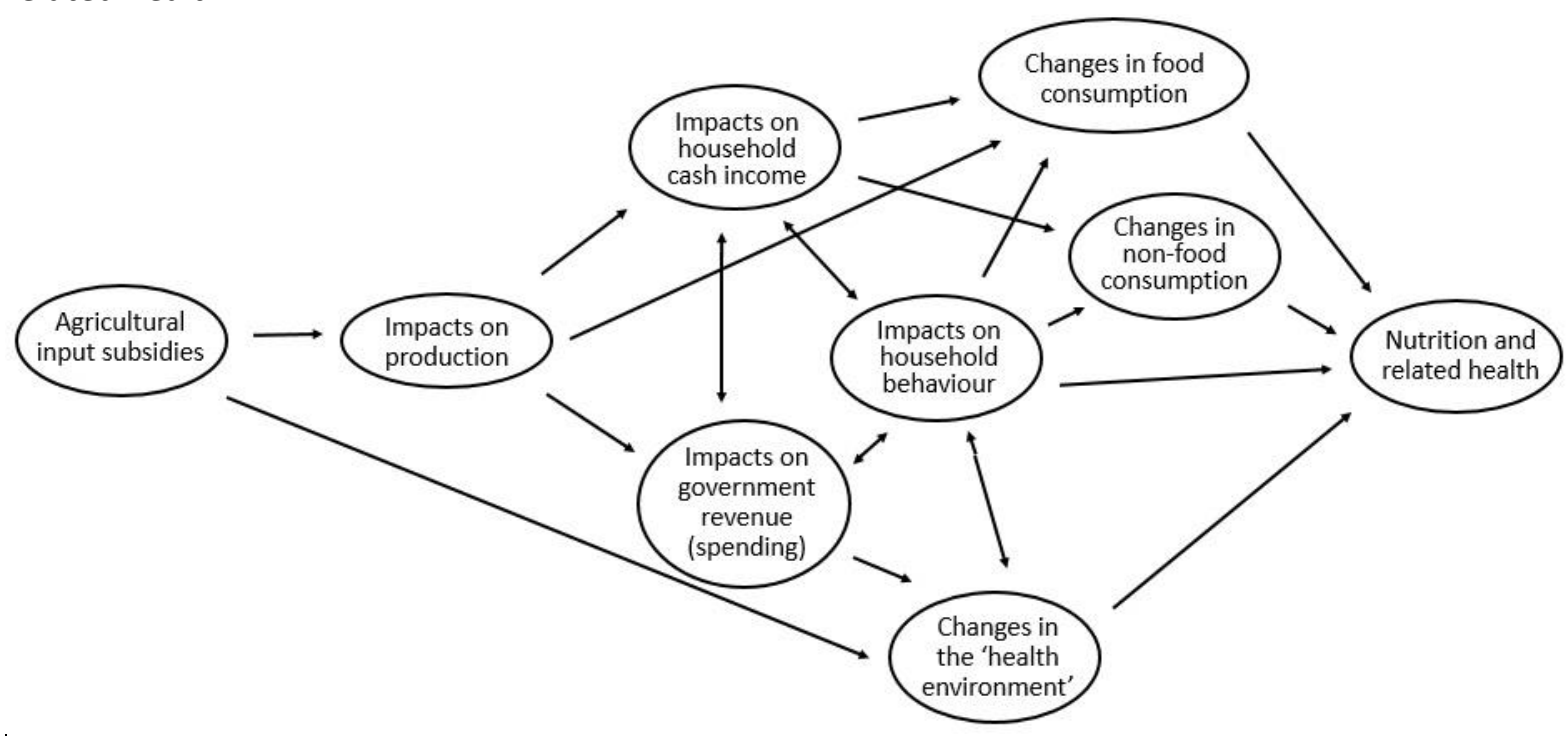

\subsection{Systematic review}

The initial search of scientific databases and online resources, undertaken by the Dorward team, resulted in 1527 publications. After obtaining these articles, we removed 76 duplicates, leaving 1451 papers. We then undertook two rounds of screening, first, based on title and abstract, and second, based on full text. One researcher (MT) screened all the publications, and two (HLW and DJ) 
screened $10 \%$ at each round. Two reviewers (MT, and one of either HLW or DJ) screened the studies independently, and double-screening was replaced by single coding after reaching a level of disagreement below $10 \%$ between the two reviewers, following recommendation and practice (Johnston et al. 2017). Agreement between three researchers (HW, MT and DJ) was reached for the publications for which there was initial disagreement regarding inclusion. All three reviewers coded each of the articles identified for final inclusion in the study. Figure 2 depicts the screening process described in the text.

\subsubsection{Screening of title and abstract}

We screened the titles and abstracts of 1451 publications for their relevance to human nutrition and nutrition-related health, and identified 460 articles. Approximately $10 \%$ of these publications (153 publications) were double-screened (i.e. screened by two reviewers, MT and HLW or DJ), and as our disagreement regarding inclusion was below $10 \%$ disagreement (9\%), after resolving these differences through discussion, the remaining publications were single-screened.

\subsubsection{Screening of full-text}

We screened the full-text of 460 publications for their relevance to nutrition and nutrition-related health. Again, approximately $10 \%$ of these publications (50 papers) were double-screened (by two reviewers, MT and HW or DJ), and we again recorded less than $10 \%$ disagreement (2\%). After resolving these differences through discussion, the remaining publications were single-screened. Any policy briefs identified were searched for original papers.

\subsubsection{Additional review}

We conducted an additional review of nine systematic reviews studying agriculture-nutrition linkages (Ruel 2001; Berti et al. 2003; Leroy and Frongillo 2007; World Bank 2007; Kawarazuka 2010; Masset et al. 2011; Girard et al. 2012; Ruel et al. 2013; Webb and Kennedy 2014) that were not identified in our systematic review but could potentially have included AIS programmes, and we also reviewed reference lists of the 11 papers identified in the previous stage to check for missing papers. From the additional search of systematic reviews, we (MT) identified seven papers for full-text review. From the review of the 11 papers we identified two additional papers for full-text review. Full texts of the 20 papers were reviewed by three co-authors (HLW, DJ and MT), of which four publications were identified for inclusion in the review. Thus, a final four publications were agreed for inclusion. 
Fig. 2 Screening process

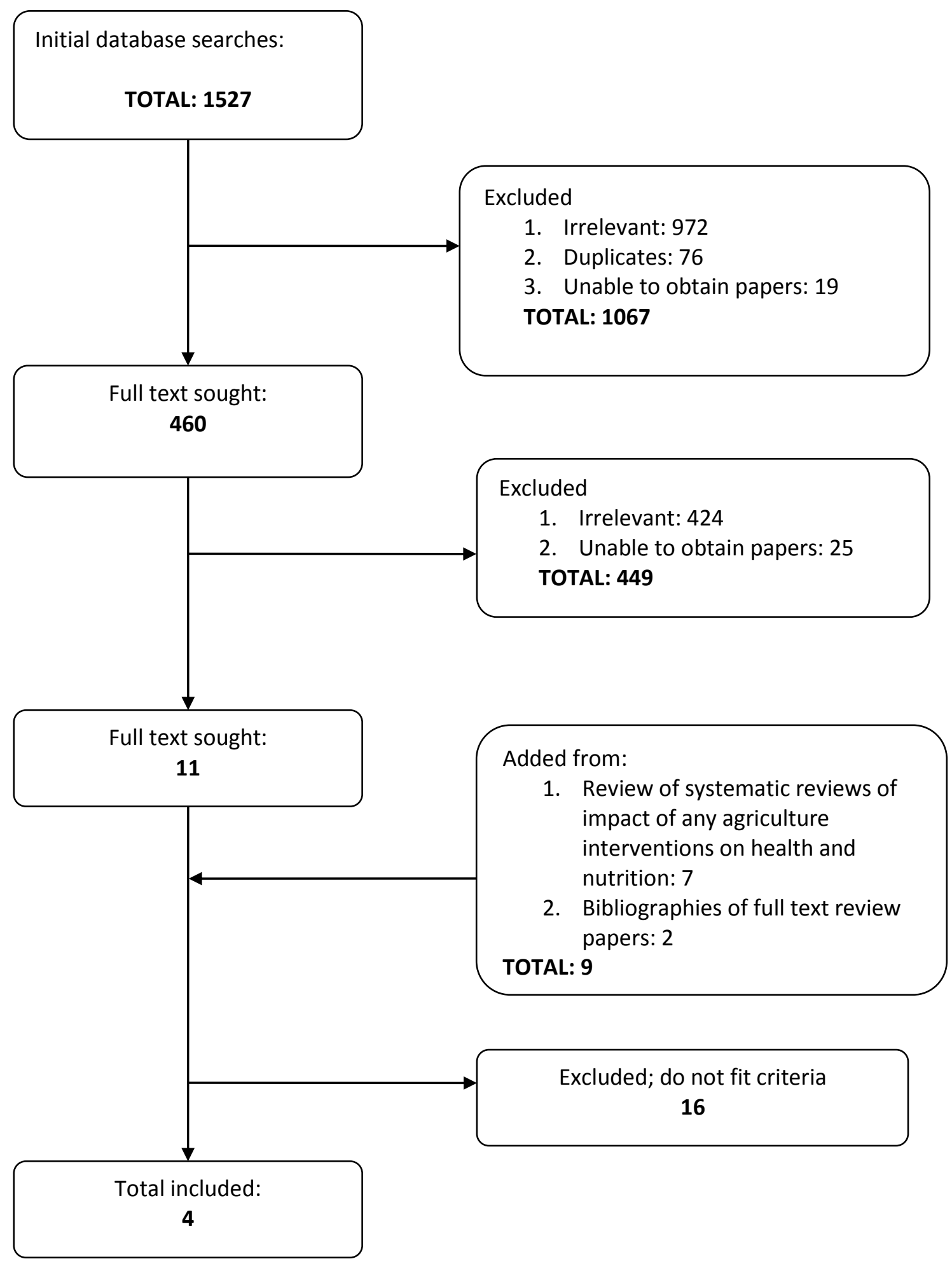

\subsection{Analysis of identified studies}

The key results from the four papers identified are presented in Table 2. 
Table 2 Key characteristics and results of the identified studies

\begin{tabular}{|c|c|c|c|c|c|c|c|}
\hline $\begin{array}{l}\text { Author } \\
\text { and year }\end{array}$ & Country & Intervention & $\begin{array}{l}\text { Primary } \\
\text { outcomes }\end{array}$ & $\begin{array}{l}\text { Secondary } \\
\text { outcomes }\end{array}$ & $\begin{array}{l}\text { Method and } \\
\text { data source }\end{array}$ & Mean result & $\begin{array}{l}\text { Pathway } \\
\text { addressed }\end{array}$ \\
\hline $\begin{array}{l}\text { Karamba } \\
(2013)\end{array}$ & Malawi & $\begin{array}{l}\text { Farm input } \\
\text { subsidy } \\
\text { programme }\end{array}$ & $\begin{array}{l}\text { Child weight- } \\
\text { for-height }\end{array}$ & $\begin{array}{l}\text { Food, non- } \\
\text { food \& health } \\
\text { consumption } \\
\text { expenditure, } \\
\text { revealed } \\
\text { optimal } \\
\text { diversity } \\
\text { (ROD) } \\
\text { (dietary) } \\
\text { index }\end{array}$ & $\begin{array}{l}\text { Regression } \\
\text { analysis } \\
\text { (instrumental } \\
\text { variable) of } \\
\text { survey data of } \\
\text { measured } \\
\text { variables } \\
(2010-11)\end{array}$ & $\begin{array}{l}\text { Positive for child } \\
\text { anthropometry. } \\
\text { Associated with greater } \\
\text { non-food expenditures, } \\
\text { not with changes in } \\
\text { food expenditures or } \\
\text { dietary diversity }\end{array}$ & $\begin{array}{l}\text { Concluded } \\
\text { impact } \\
\text { through non- } \\
\text { food } \\
\text { consumption } \\
\text { pathways. }\end{array}$ \\
\hline $\begin{array}{l}\text { Holden } \\
\text { and } \\
\text { Lunduka } \\
\text { (2013) }\end{array}$ & Malawi & $\begin{array}{l}\text { Farm input } \\
\text { subsidy } \\
\text { programme }\end{array}$ & Child health & $\begin{array}{l}\text { Consumption } \\
\text { of maize, } \\
\text { effect on } \\
\text { household } \\
\text { food security }\end{array}$ & $\begin{array}{l}\text { Regression } \\
\text { and basis } \\
\text { statistical } \\
\text { analysis of } \\
\text { survey data of } \\
\text { participant } \\
\text { perception } \\
(2007-09)\end{array}$ & $\begin{array}{l}\text { Positive effects on child } \\
\text { health (and school } \\
\text { attendance), on } \\
\text { household food } \\
\text { security, and on maize } \\
\text { consumption }\end{array}$ & Not discussed \\
\hline $\begin{array}{l}\text { Chirwa et } \\
\text { al. (2011) }\end{array}$ & Malawi & $\begin{array}{l}\text { Farm input } \\
\text { subsidy } \\
\text { programme }\end{array}$ & $\begin{array}{l}\text { Incidence of } \\
\text { under-5 } \\
\text { illness, coping } \\
\text { strategy index } \\
\text { (CSI) }\end{array}$ & $\begin{array}{l}\text { Food } \\
\text { consumption } \\
\text { (cereal/fruit, } \\
\text { fish/meat, } \\
\text { vegetables) }\end{array}$ & $\begin{array}{l}\text { Regression } \\
\text { analysis of the } \\
\text { third Farm } \\
\text { Input Subsidy } \\
\text { Survey (FISS3) } \\
\text { (2011) }\end{array}$ & $\begin{array}{l}\text { Positive effect on child } \\
\text { health (in female and } \\
\text { younger-headed } \\
\text { households), mixed } \\
\text { impacts on food } \\
\text { security measures, } \\
\text { positive impact on } \\
\text { consumption of various } \\
\text { food types. No change } \\
\text { for overall food } \\
\text { consumption }\end{array}$ & $\begin{array}{l}\text { Concluded } \\
\text { impact } \\
\text { through food } \\
\text { consumption, } \\
\text { income and } \\
\text { gender } \\
\text { pathways }\end{array}$ \\
\hline $\begin{array}{l}\text { von Braun } \\
\text { (1988) }\end{array}$ & $\begin{array}{l}\text { The } \\
\text { Gambia }\end{array}$ & $\begin{array}{l}\text { Rice } \\
\text { production } \\
\text { (irrigation) } \\
\text { technology }\end{array}$ & $\begin{array}{l}\text { Household } \\
\text { energy } \\
\text { consumption, } \\
\text { women's } \\
\text { weight-for- } \\
\text { height, child } \\
\text { height and } \\
\text { weight for } \\
\text { age }\end{array}$ & - & $\begin{array}{l}\text { Regression } \\
\text { analysis of a } \\
\text { farm } \\
\text { household } \\
\text { survey (1985- } \\
\text { 6) }\end{array}$ & $\begin{array}{l}\text { Increase in energy } \\
\text { consumption (not } \\
\text { correlated with } \\
\text { household cereal } \\
\text { production, but with } \\
\text { women's share of } \\
\text { cereal production), less } \\
\text { seasonal fluctuation in } \\
\text { women's weight, } \\
\text { increase in child weight } \\
\text { and height }\end{array}$ & $\begin{array}{l}\text { Concluded } \\
\text { impact } \\
\text { through food } \\
\text { consumption, } \\
\text { income and } \\
\text { gender } \\
\text { pathways }\end{array}$ \\
\hline
\end{tabular}

Of the four papers identified, three are of an AIS programme in Malawi, the country's 'Farm Input Subsidy Programme' (FISP) and one is a study of rice production technology in The Gambia.

As none of the studies were experimental or quasi-experimental, in order to review the quality of the methodology used by the selected studies, we extend the approach used by Cirera et al. (2011), Dorward et al. (2014) and Johnston et al. (2015) for non-randomised studies. This involved 
assessing study design on the basis of: i) data used; ii) methodology used; iii) model specification; iv) methods of inference; and $v$ ) whether the study was peer reviewed. Model specification was assessed based on the strength of the estimation technique and how the authors addressed endogeneity concerns. The methods of inference were assessed by relevance of outcome variables to nutrition.

Three studies were based on measured survey data, while one in Malawi (by Holden and Lunduka 2013) was based on a household perception survey. In terms of methodology type, there was little diversity, with all four studies using regression analysis of survey data. Model specification was also assessed. Each of the studies considered confounding factors and tested the results for statistical significance. In terms of methods of inference, each of the papers included only a few measures related to our primary outcomes of 'nutrition and related health' - and there was considerable variation in indicator types chosen, although child health outcomes were often addressed. With outcomes that we considered 'secondary measures', food consumption was often included, and two papers included measures of dietary diversity, but this was addressed narrowly with limited reporting of detail, although in saying this, dietary diversity was not the primary outcome of interest in these studies. Of the four studies, two were sourced from the grey literature (Karamba 2013; Chirwa et al. 2011), and two receive the higher quality consideration accorded peerreviewed academic journal articles (Holden and Lunduka 2013; von Braun 1988). Overall, each study scored as medium to high quality.

The results from the studies of Malawi's FISP were mixed, but overall positive in the effects of the programme on chosen measures of nutrition and related health. Karamba (2013) found that FISP participation was positively associated with child weight-for-height, particularly for boys. The study also reported that the FISP influences child health via non-food consumption rather than the food consumption pathway as FISP participation was not found to be associated with greater food expenditure or dietary diversity. Chirwa et al. (2011) found similarly positive (although fairly mixed) results from their analysis of the 2010/11 survey data for Malawi. Based on this cross-sectional study, households with access to the FISP were five times less likely to have ill children under the age of five years, however the impacts of child health may only be in female and younger-headed households. Households participating in the FISP also tended to consume more maize, vegetables and meat products compared to non-recipient households, although there was no impact found on overall consumption. The Holden and Lunduka (2013) study found that $40 \%$ of the households believed the FISP had positive effects on children's health and two-thirds considered it to have positive impact on household food security. Two studies, by Karamba (2013) and Chirwa et al. (2011), both evaluating Malawi's FISP using regression analysis, found similar results for impact of the FISP on health, however provide different findings on dietary diversity. Karamba (2013) found no statistically significant relationship, whilst Chirwa et al. (2011) found a positive association with type of foods consumed, a proxy measure for dietary diversity.

The study of van Braun (1988) reporting the impact of rice irrigation technology in The Gambia found an increase in energy consumption, and less seasonal fluctuation in women's weight and improved child anthropometric measures. In this study, higher yields were associated with lower women's participation, but the authors hypothesise that a higher share of cereals produced under women's control had a positive effect on consumption over and above the income effect of cereal production - an example of a non-food pathway of impact. 
Of the three studies that discussed pathways of impact (two for Malawi, one for The Gambia), all suggested impact through household income, two suggested impact through changes in food consumption, and two through changes to women's empowerment. One study (from Malawi) suggested a pathway through non-food consumption (specifically, though greater non-food expenditure) rather than through food consumption or increases in dietary diversity. Figure 3 depicts this pictorially, with rings representing the number of studies addressing each of the framework domains.

Fig. 3 Depiction of the areas of the framework addressed and not addressed by the reviewed studies

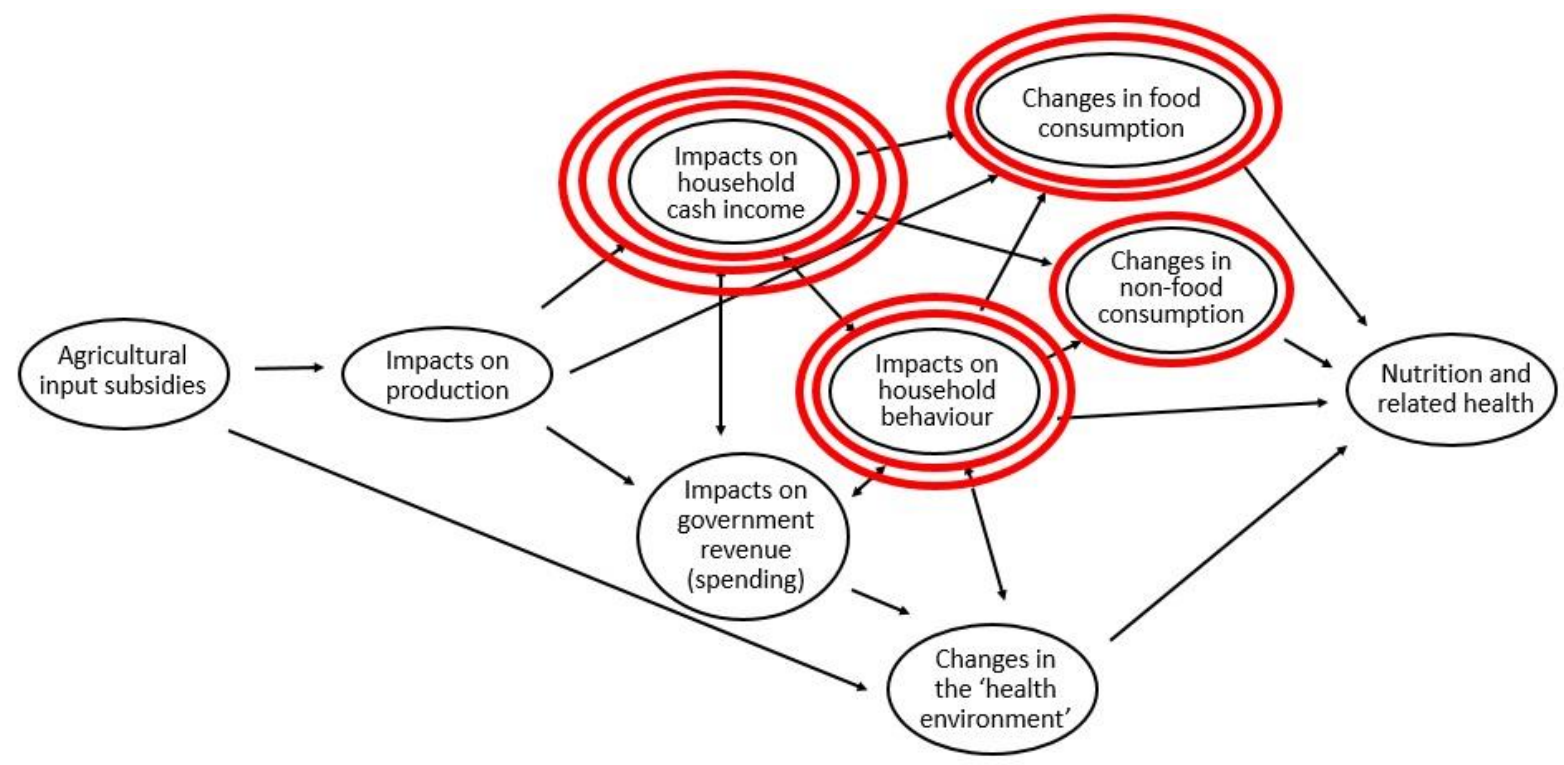

Note: The circles surrounding the domains each depict that that particular domain was addressed by a study. For example, 'impacts on household cash income' has 3 additional circles around it as 3 studies described impact through this domain, whereas 'changes in non-food consumption' has 1 additional circles around it as only 1 study described impact through this domain.

Two of the four papers (one for Malawi, one for The Gambia) examined the role of gender in their analyses. Chirwa et al. (2011) found that the incidence of illness amongst under five year olds was lower only in female-headed (and younger-headed) households. von Braun (1998) reported that even though the rice irrigation technology had a positive impact on health and calorie intake of both women and children, the introduction of new technology implied a shift of income away from women to men, which in turn led to a decline in calorie consumption when controlled for income.

\section{Discussion}

Our review identified only four papers addressing the impact of AISs on nutrition and related health. Three of these were of Malawi's FISP from post-2010, and one was of a rice technology study from The Gambia from the mid-1980s. Whilst not wanting to place undue emphasis on the results of such a small number of studies, the results from the four studies - whilst mixed and sometimes contradictory - overall suggest a positive impact of AISs on nutrition and health. However the review also highlights a need for considerable more research, and more recent research. 
The suggested pathways for the impact of AISs on nutrition and health differ between studies. In the four studies assessed, the suggested pathways of impact were through agricultural production, household income, household behaviour and gender dimensions, and changes in food consumption and/or non-food consumption. Impacts through government revenue (and spending) and changes in the 'health environment', as shown in Fig. 3, were not found. The diversity in the suggested pathways of impact may reflect local conditions - including household and gender dynamics - as well as programme design, indicating that this is an area in need of further investigation.

Interpretation of differences in the findings from the studies of Malawi's FISP, first implemented in 2005/06, should be mindful of the considerable changes the FISP has undergone over time to address difficulties, improve performance and broaden impact (Dorward and Chirwa 2011; Karamba 2013; Harman et al. 2016). The FISP, a large-scale AIS with two-fifths of the country's population as direct beneficiaries (Arndt et al. 2015), aims to support agricultural production, primarily maize productivity and output, and is administered through vouchers that enable eligible households to purchase fertiliser, hybrid seeds and pesticides at reduced prices (Harman et al. 2016). The most common types of vouchers have been for maize seed and fertiliser, at times, legume seeds have also been subsidised (Dorward and Chirwa 2011; Karamba 2013; Snapp and Fisher 2015). Thus, given the changes, the three studies were likely of slightly different FISP 'versions', with the Karamba (2013) and Chirwa et al. (2013) studies being the most recent.

There are a number of limitations to our review. A key challenge was determining what constituted an AIS. Based on our definition of an AIS, 'policies/programmes designed explicitly to reduce the input costs of agricultural activities', it was difficult to determine whether, for example, home garden projects which include provision of free seeds should be included, or irrigation where its provision was subsidised. We chose not to include small-scale interventions such as home gardening, but subsidies of rice irrigation were included. As discussed in the methods, we also chose not to include studies of large agricultural changes that may include AIS as a component, for example studies of the 'green revolution', of which we encountered several examples. It is possible that we may have missed some studies of AIS that did not use search terms of 'input subsidy' in the initial search, and this may apply particularly to disciplinary papers not linked explicitly to agriculture.

During the review we became aware of a considerable amount of literature that examines aspects of the causal pathway from AISs to nutrition and/or health, but not the full pathway itself. This is particularly the case in relation to end-points more proximal to the subsidy, such as agricultural production or household income. Of studies more distal to the AIS, and proximal to nutrition and health outcomes, a number have assessed AIS impact on food prices. For example, in studies of Malawi, Dorward et al. (2011) and Ricker-Gilbert (2013) found weak evidence (Dorward and Chirwa 2011) and minimal evidence (Ricker-Gilbert et al. 2013) respectively, that the FISP increased maize production and reduced its price.

However, as we saw earlier, AISs are often criticised for focusing on staples, which can be high in calories but low in other vital nutrients. This wider consideration of impacts on dietary diversity rather than on a single crop is important, given the increasing recognition in nutrition policy of the importance of dietary diversity (Burchi et al. 2011; Thompson and Meerman 2013; Koppmair et al. 2017). Indeed, Malawi's FISP has been critiqued for perpetuating a dependency on maize 
(Harrigan 2008; Chibwana et al. 2012). Thus, food price elasticities should be taken into account, rather than just effects on the price of maize. A cheaper price of maize in Malawi due to its FISP could mean people consume more maize, or could enable greater expenditure on other products, including food, and resulting substitution patterns may reinforce or undermine the direct impact of a price reduction (Green et al. 2013; Cornelsen et al. 2014). An increasing body of literature studies price elasticities of demand, including for example in Malawi (Ecker and Qaim 2011; Harttgen et al. 2016), but few have linked these to AISs. More proximal to nutrition and health but not including these, some studies have linked AISs to food availability and/or consumption. For example, Snapp and Fisher (2015), publishing after the period of our systematic review, examined the impact of Malawi's FISP on crop diversity and quality of diets, concluding weak evidence of a positive impact on both (Snapp and Fisher 2015).

Gender as an important mediator of the impact of AISs on nutrition and health was discussed in two of the four studies, and we suggest more attention is also needed to this. Women are often in charge of food budgeting and purchasing decisions, and may have different food acquisition strategies to male-headed households under an AIS programme due to different opportunities and to constraints, including time constraints (Chibwana et al. 2012). We might similarly expect different responses by socio-economic status, with poorer households likely to spend a larger share of household income on food and have less dietary diversity (Melgar-Quinonez et al. 2006; Thorne-Lyman et al. 2010), and also expect net producers and net consumers to be differently affected (Peters 1996).

In addition to research of AIS impact, much more is also needed on the context of the impact. As observed by Harman et al. (2016), there has also been little qualitative work undertaken generally of Malawi's AIS programme to help understand any quantitative findings regarding impacts of the FISP (Harman et al. 2016).

\section{Conclusion and recommendations}

Both impact and its context are poorly understood but crucial for nutrition-sensitive policy-making. Given the financial resources devoted to AIS in some countries (and resurgence of interest in AIS programmes), this is an important area to be addressed. Crucially, it also needs to be considered in countries other than Malawi, as AIS programmes are or have been in place in many other countries, for example for Sub-Saharan Africa, and Baltzer and Hansen (2012) have evaluated AISs in Malawi, Zambia, Ghana and Tanzania (though not in relation to nutrition and related health).

Investment in AIS programmes has potential to raise agricultural productivity, with development benefits including through improved diets, and many LMICs have implemented such policies or are interested in doing so. However, little is known of the impact on nutrition and related health, nor the wider context of AIS programme implementation and effect on food choices including in regard to local markets and food choices, diets, and household dynamics, including gender effects. Further research is needed in this area to provide nutrition and agriculture policymakers a far more nuanced and contextual understanding of AIS impact on food choices and consumption, including on wider dietary patterns, and thus support development of nutritionsensitive policy-making. 
In conclusion, large investment in AIS programmes has been made in some countries, often with intended consequences for nutrition and health, but little is known of the magnitude and pathways of this impact, or its context. Given these substantial gaps in knowledge, we recommend these as key areas for further research.

Acknowledgements We would like to thank the London International Development Centre (LIDC) Interdisciplinary Seed Fund (awarded to HLW and DJ) for supporting this work, and advice received from Dr Karen Lock, Dr Carlos Oya and Dr Sara Stevano. HLW was part-funded by the Leverhulme Centre for Integrative Research on Agriculture and Health.

\section{Conflict of interest}

The authors have no conflicts of interest to declare.

\section{References}

Arndt, C., Pauw, K. \& Thurlow, J. (2016). The Economy-wide Impacts and Risks of Malawi's Farm Input Subsidy Program. American Journal of Agricultural Economics, 98(3), 962-980.

Baltzer, K. \& Hansen, H. (2012). Agricultural input subsidies in Sub-Saharan Africa. Ministry of Foreign Affairs of Denmark. Available at: https://www.oecd.org/derec/49231998.pdf (accessed 24 February 2018).

Berti, P., Krasevec, J. \& Fitzgerald, S. (2003). A review of the effectiveness of agricultural interventions in improving nutrition outcomes. Public Health Nutrition, 7, 599-609.

Burchi, F., Fanzo, J. \& Frison, E. (2011). The role of food and nutrition system approaches in tackling hidden hunger. International Journal of Environmental Research and Public Health, 8(2), 358-373.

Chibwana, C., Fischer, M. \& Shively, G. (2012). Cropland allocation effects of agricultural input subsidies in Malawi. World Development, 40(1), 124-133.

Chirwa, E., Matita, M., Mvula, P. \& Dorward, A. (2011). Impact of the Farm Inut Subsidy Programme in Malawi. Available at: http://wadonda.com/Chirwa_et_al_2011_FISP10_Impacts.pdf (accessed 24 February 2018)

Cirera, X., Willenbockel, D. \& Lakshman, R. (2011). What is the evidence of the impact of tariff reductions on employment and fiscal revenue in developing countries? Technical report. London, EPPI-Centre, Social Science Research Unit, Institute of Education, University of London.

Cornelsen, L., Green, R., Dangour, A. \& Smith, R. (2014). Why fat taxes won't make us slim. Journal of Public Health, 37(1), 18-23. 
Dorward, A. \& Chirwa, E. (2011). The Malawi Agricultrural Input Subsidy Programme: 2005-6 to 2008-9. International Journal of Agricultural Sustainability, 9(1), 232-247.

Dorward, A., Roberts, P., Finegold, C., Hemming, D., Chirwa, E., Wright, H., Hill, R. et al. (2014). Protocol: Agricultural Input Subsidies for improving Productivity, Farm Income, Consumer Welfare and Wider Growth in Low- and Middle-Income Countries: A Systematic Review. The Campbell Collaboration, London.

Dorward, A., Roberts, P., Finegold, C., Hemming, D., Chirwa, E., Wright, H., Hill, R. et al. (2015). Agricultural input subsidies for improving productivity, farm income, consumer welfare and wider growth in low- and middle-income countries: A systematic review. In progress.

Ecker, O. \& Qaim, M. (2011). Analysing nutritional impacts of policies: an emprical study of Malawi. World Development, 39(3), 412-428.

Girard, A., Self, J., McAuliffe, C. \& Olude, O. (2012). The effects of household food production strategies on the health and nutrition outcomes of women and young children: a systematic review. Paediatric Perinatal Epidemiology, 26(Suppl 1), 205-222.

Gordon, A. (2000). Improving Smallholder access to purchased inputs in Sub-Saharan Africa. Policy Series 7. University of Greenwich, London, UK, Natural Resources Institute.

Green, R., Cornelsen, L., Dangour, A., Turner, R., Shankar, B., Mazzocchi, M., \& Smith, R. (2013). The effect of rising food prices on food consumption: systematic review with meta-regression. British Medical Journal, 346, f3703.

Harman, L., Dorward, A., \& Goodman, C. (2016). 'No room for talking': understanding the drivers of beneficiary-level targeting outcomes in Malawi's Farm Input Subsidy Programme. In Preparation.

Harrigan, J. (2008). Food insecurity, poverty and the Malawian starter pack: Fresh start or false start? Food Policy, 33(3), 237-249.

Harttgen, K., Klasen, S. \& Rischke, R. (2016). Analyzing nutritional impacts of price and income related shocks in Malawi: Simulating household entitlements to food. Food Policy, 60, 31-43.

Holden, S. \& Lunduka, R. (2013). Who benefits from Malawi's targeted farm input subsidy program? Forum for Development Studies, 40(1), 1-25.

Jayne, T. \& Rashid, S. (2013). Input subsidy programs in sub-Saharan Africa: a synthesis of recent evidence. Agricultural Economics, 44(6), 547-562.

Johnston, D., Stevano, S., Hazel, M., Elizabeth, H. \& Suneetha, K. (2015). Agriculture, Gendered Time Use, and Nutritional Outcomes: A Systematic Review. International Food Policy Research Institute (IFPRI).

Johnston, D., Stevano, S., Malapit, H., Hull, E. \& Kadiyala, S. (2018). Time us as an explanation for the agri-nutrition disconnect? A systematic review of evidence from rural areas in low- and middle-income countries. Food Policy, Available online. 
Kanter, R., Walls, H., Tak, M., Roberts, F. \& Waage, J. (2015). A conceptual framework for understanding the impacts of agriculture and food system policies on nutrition and health. Food Security, 7(4), 767-777.

Karamba, R. (2013). Input subsidies and their effect on cropland allocation, agrocultural productivity, and child nutrition: Evidence from Malawi. Thesis, Doctor of Philosophy in Economics, American University Washington.

Kawarazuka, N. (2010). The contribution of fish intake, aquaculture, and smallscale fisheries to improving food and nutrition security: A literature review. Penang, Malaysia:, The World Fish Center.

Koppmair, S., Kassie, M. \& Qaim, M. (2017). Farm production, market access and dietary diversity in Malawi. Public Health Nutrition, 20(2), 325-335.

Leroy, J. \& Frongillo, E. (2007). Can Interventions to Promote Animal Production Ameliorate Undernutrition? The Journal of Nutrition, 137, 2311-2316.

Masset, E., Haddad, L., Cornelius, A. \& Isaza-Castro, J. (2011). A systematic review of agricultural interventions that aim to improve nutritional status of children. London, EPPI-Centre, Social Science Research Unit, Institute of Education, University of London.

Melgar-Quinonez, H., Zubieta, A., MkNelly, B., Nteziyaremye, A., Gerardo, M. \& Dunford, C. (2006). Household food insecurity and food expenditure in Bolivia, Burkina Faso, and the Philippines. Journal of Nutrition, 136(5), 1431S-1437S.

Morris, M., Kelly, V., Kopicki, R. \& Byerlee, D. (2007). Fertilizer use in African agriculture. Directions in Development: Agriculture and Development. 39037. Washington, D.C., USA, World Bank.

Peters, P. (1996). Failed Magic or Social Context?: Market Liberalization and the Rural Poor in Malawi. Harvard Institute for International Development, Harvard University, USA.

Ricker-Gilbert, T., Mason, N., Jayne, T., Darko, F. \& Tembo, S. (2013). What are the effects of input subsidy programs on equilibrium maize prices? Evidence from Malawi and Zambia. Available at: http://ageconsearch.umn.edu/bitstream/149259/2/maize_price_AAEA_final_submit.pdf (accessed 24 February 2018).

Ruel, M. (2001). Can Food-Based Strategies Help Reduce Vitamin A and Iron Deficiencies? A Review of Recent Evidence. Washington DC, International Food Policy Research Institute.

Ruel, M., Alderman, H. \& Maternal and Child Nutrition Study Group. (2013). Nutrition-sensitive interventions and programmes: How can they help to accelerate progress in improving maternal and child nutrition? The Lancet, 382(9891), 536-551.

Snapp, S. \& Fisher, M. (2015). "Filling the maize basket" supports crop diversity and quality of househould diet in Malawi. Food Security, 7(1), 83-96.

Snilstveit, B., Oliver, S. \& Vojtkova, M. (2012). Narrative approaches to systematic review and synthesis of evidence for international development policy and practice. Journal of Development Effectiveness, 4(3), 409-429. 
Thomas, J. \& Harden, A. (2008). Methods for the thematic synthesis of qualitative research in systematic reviews. BMC Medical Research Methodolology, 8, 45. Available at: http://www.fao.org/fileadmin/user_upload/agn/pdf/Narrowing_Nutrition_Gap_2013.pdf (accessed 24 February 2018).

Thompson, B. \& Meerman, J. (2013). Narrowing the nutrition gap: Investing in agriculture to improve dietary diversity.

Thorne-Lyman, A., Valpiani, N., Sun, K., Semba, R., Klotz, C., Kraemer, K., Akhter, N. et al. (2010). Household dietary diversity and food expenditures are closely linked in rural Bangladesh, increasing the risk of malnutrition due to the financial crisis. The Journal of Nutrition, 140(1), 182S-188S.

Turner, R., Hawkes, C., Waage, J., Ferguson, E., Haseen, F., Holmans, H. et al. (2013). Agriculture for improved nutrition: the current research landscape. Food and Nutrition Bulletin, 34(4), 369-377.

UNICEF. (2010). UNICEF conceptual framework. Available at:

http://www.unicef.org/nutrition/training/2.5/4.html (accessed 24 February 2018).

von Braun, J. (1988). Effects of technological change in agriculture on food consumption and nutrition: Rice in a West African setting. World Development, 16(9), 1083-1098.

Webb, P. \& Kennedy, E. (2014). Impacts of agriculture on nutrition: nature of the evidence and research gaps. Food Nutrition Bulletin, 35(1), 126-132.

Wiggins, S. \& Brooks, J. (2010). The Use of Input Subsidies in Developing Countries. The Organisation for Economic Co-operation and Development, Presented to the Working Party on Agricultural Policy and Markets, Global Forum on Agriculture, 15-17 November 2010. Available at: https://www.oecd.org/tad/agricultural-policies/46340359.pdf (last accedded 24 February 2018).

World Bank (2007). From Agriculture to Nutrition: Pathways, Synergies and Outcomes. Washington DC, The World Bank Agriculture and Rural Development Department. 